\title{
Minimally invasive treatment of intrahepatic cholangiolithiasis after stricture of hepaticojejunal anastomosis
}

\author{
Aliaksandr Varabei ${ }^{1}$, Yury Arlouski ${ }^{1}$, Natalli Lagodich $^{1}$, Vitaly Arehay $^{2}$ \\ ${ }^{1}$ Belarusian Medical Academy of Post-Graduate Education, Minsk, Belarus \\ ${ }^{2}$ N.N. Alexandrov National Cancer Centre of Belarus, Minsk, Belarus
}

Videosurgery Miniinv 2018; 13 (1): 111-115

DOI: https://doi.org/10.5114/wiitm.2018.72667

\begin{abstract}
The aim of the study was to improve the results of treatment of patients with intrahepatic cholangiolithiasis for hepaticojejunostomy stricture with use of miniinvasive methods. In our centre during the period from 2002 till 2016 were treated in 58 patients with hepaticojejunostomy strictures. Thirteen patients from their was coexistant intrahepatic cholangiolithiasis. Forty-six (79.3\%) patients was performed rehepaticojejunostomy. Twelve patients was performed a minimally invasive intervention such as laser recanalisation using double balloon enteroscopy (7 patients) and lithoextraction with double balloon enteroscopy (1), transhepatic cholangioscopy (2 patients) with laser lithotripsy (1), balloon dilatation of the stricture rehepaticojejunostomosis (4), lithoextraction (4), including with double balloon enteroscopy ("randevoux" procedure) (1), stenting (2). We observed several complication such as cholangitis (5); recurrent cholangiolithiasis (1); restricture of rehepaticojejunostomosis (2). Miniinvasive endoscopic techniques treatment and endobiliary correction of rehepaticojejunostomosis strictures and cholangiolithiasis have shown good results.
\end{abstract}

Key words: stricture, hepaticojejunoanastomosis, double balloon enteroscopy, lithotripsy, cholangiolithiasis.

\section{Introduction}

Benign strictures of hepaticojejunal anastomoses (HJA) are observed in $10-30 \%$ of cases after reconstructive operations on the bile ducts $[1,2]$. However, from $62.3 \%$ to $75 \%$ of such patients are reported to be subjected to repeated operations for recurrent anastomotic strictures [3, 4].

Quite often this pathology may be complicated by recurrent cholangitis, cholangiolithiasis, hepatic failure and liver cirrhosis $[5,6]$. According to Negi et al., liver cirrhosis resulting from biliary obstruction can develop within 3.8-14.8 months of the postoperative period [7].

Traditionally, repeated reconstructive surgery for strictures of HJA and cholangiolithiasis is associated with traumatic interventions decreasing the quality of patients' lives and increasing the risk of their developing recurrent stricture formation [8]. According to Bismuth, in 60-90\% of cases each subsequent operation leads to stricture level type IV-V $[9,10]$.

\section{Case report}

On December 12, 2016 a 70-year-old woman was admitted to our center with complaints of abdominal pain, jaundice, and fever. Previously, in 2014, she had been subjected to a pancreatoduodenal resection for ductal adenocarcinoma. Since February 2016 she had had clinical manifestations of cholangitis: periodic abdominal pain, temperature up to $38^{\circ} \mathrm{C}$, and icteric skin. According to the data obtained through the magnetic resonance cholangiography in October 6, 2016, the patient's intrahepatic ducts

\section{Address for correspondence}

Prof. Aliaksandr Varabei, Belarusian Medical Academy of Post-Graduate Education, Lesnoe 1, Minsk District, 223041 Minsk, Belarus, phone: +37 5296554717, e-mail: dept-surg@hotmail.com 


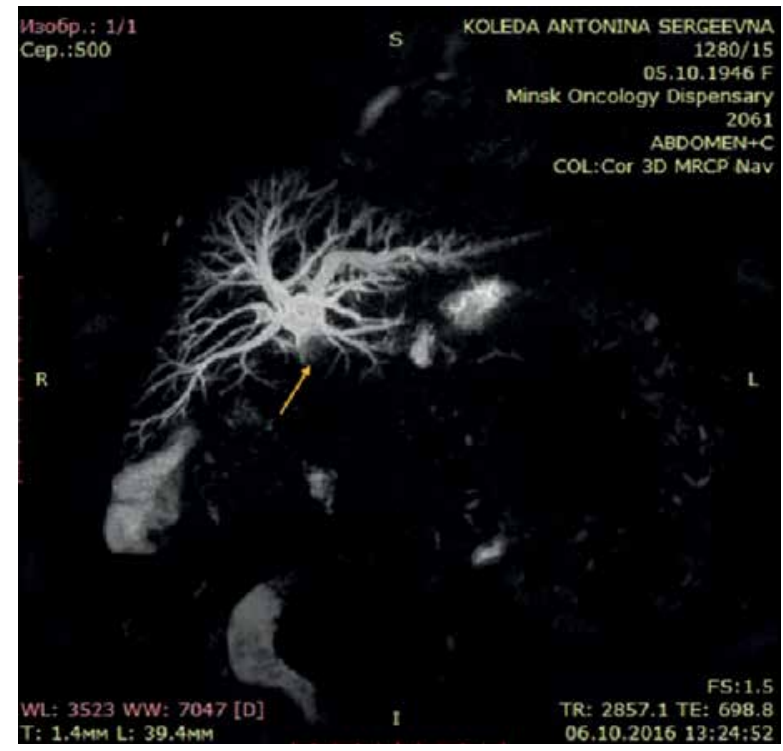

Photo 1. Magnetic resonance cholangiography: a concrement in the hepatic duct above the HJA (note the arrow)

were enlarged. She had a common hepatic duct (CHD) length of $21 \mathrm{~mm}$ with an oval-shaped intraluminal filling defect of $21 \times 9 \mathrm{~mm}$, while the distal common bile duct was not visualized (Photo 1 ).

In December 22, 2016 the patient was subjected to a combined minimally invasive treatment with simultaneous double-balloon enteroscopy (DBE) of the Roux-en-Y loop under the guidance of percutaneous

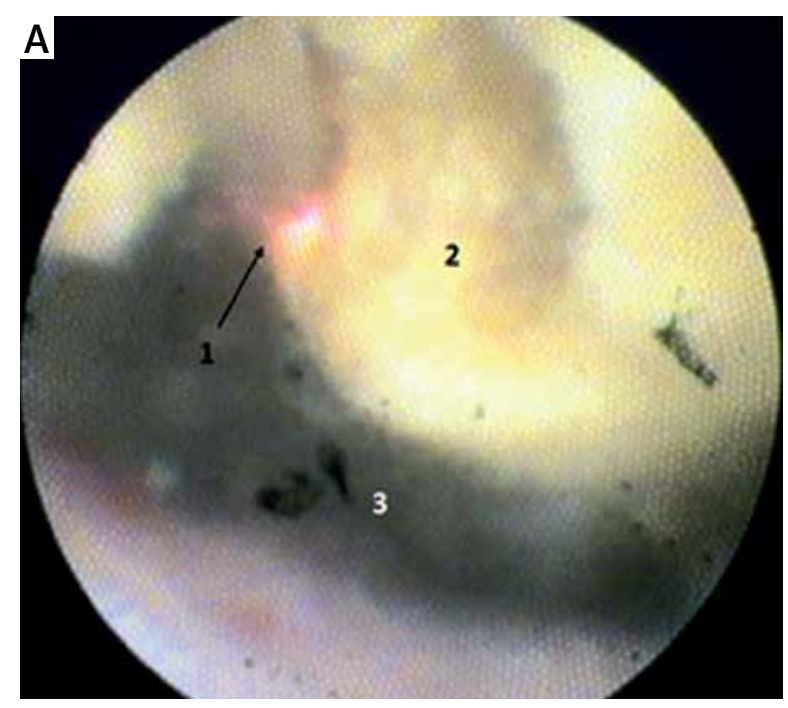

Photo 3. Percutaneous transhepatic cholangioscopy: A - direct visualization of a concrement in CHD and its laser lithotripsy (1 - laser light guide, 2 - concrement, 3 - the lumen of CHD); B - the result of lithotripsy (arrows indicate concrement fragments)
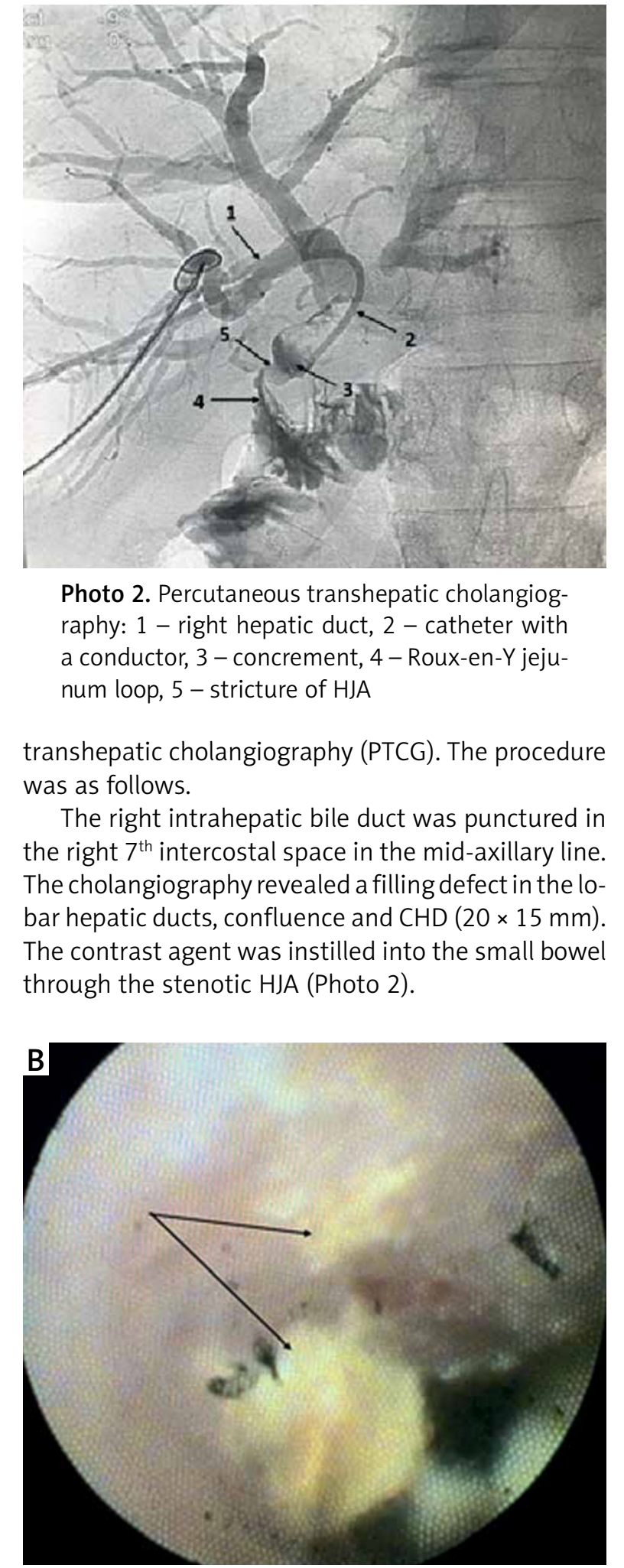

Photo 2. Percutaneous transhepatic cholangiography: 1 - right hepatic duct, 2 - catheter with a conductor, 3 - concrement, 4 - Roux-en-Y jejunum loop, 5 - stricture of HJA

transhepatic cholangiography (PTCG). The procedure was as follows.

The right intrahepatic bile duct was punctured in the right $7^{\text {th }}$ intercostal space in the mid-axillary line. The cholangiography revealed a filling defect in the lobar hepatic ducts, confluence and CHD $(20 \times 15 \mathrm{~mm})$. The contrast agent was instilled into the small bowel through the stenotic HJA (Photo 2). 
We performed the recanalization of the HJA using a conductor and a catheter. A $10 \mathrm{Fr}$ introducer was inserted into the lumen of the bile ducts, through which the lumen became accessible by a cholangioscope. A dense concrement obturating the duct lumen and the zone of anastomosis was visualized in the area of the confluence and the HJA (Photo $3 \mathrm{~A}$ ). This manipulation allowed for laser lithotripsy of the concrement (wavelength of $1440 \mathrm{~nm}$, power of $12 \mathrm{~W}$ ) (Photo $3 \mathrm{~B}$ ).

The lithotripsy through the conductor was followed by balloon dilatation of the HJA with subsequent transportation of the stones below the anastomosis into the jejunum (Photo 4).

After the double-balloon-enteroscope (DBE) was retrieved to the anastomosis zone, the concrement obturating the lumen was removed with a Dormia basket inserted through the working channel of the DBE (Photo 5).

\section{Discussion}

Recently, there has been observed a tendency to frequently use minimally invasive methods for the diagnosis and treatment of cholangiolithiasis and strictures of HJA: percutaneous transhepatic biliary drainage, PTCG with balloon dilatation of the anastomosis, lithotripsy with lithoextraction using DBE, and stenting [11-13]. According to Mueller et al., the efficacy of percutaneous transhepatic interventions for strictures of HJA ranges from $67 \%$ to $73 \%$ [14]. However, when used separately, these methods are not always effective. There are also technical diffi-
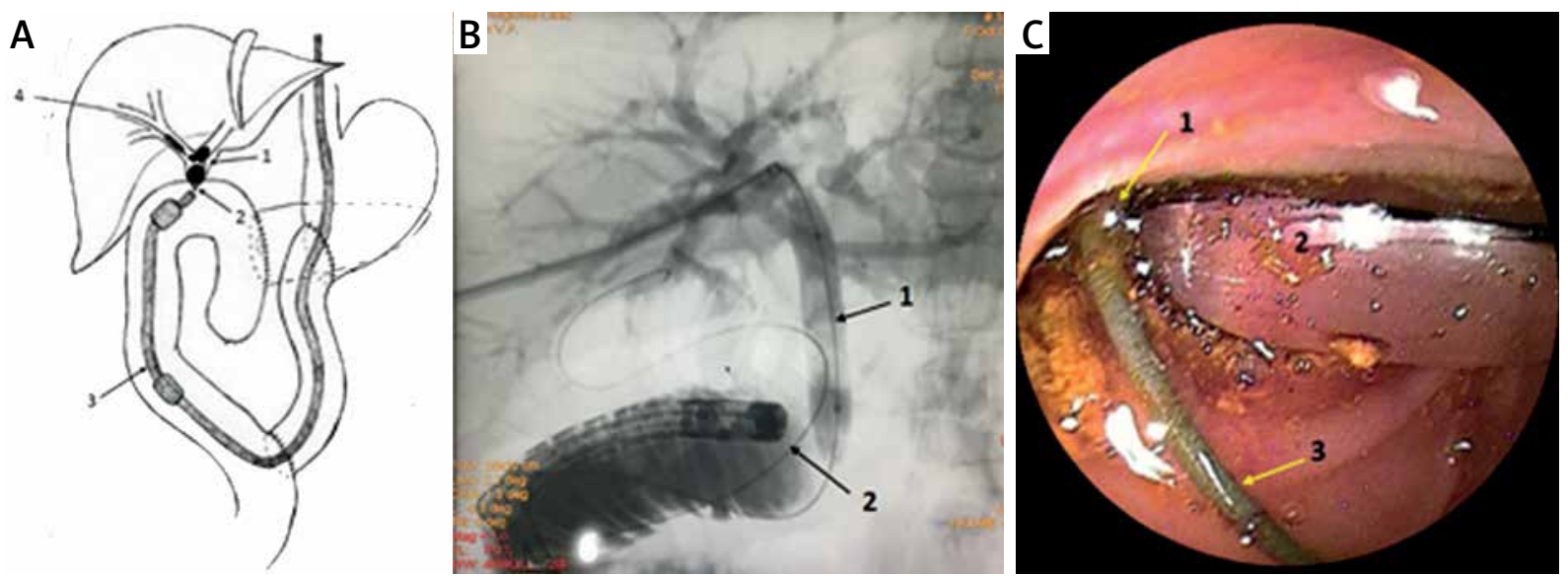

Photo 4. Balloon dilatation of HJA: A - scheme of procedure (1 - zone of HJA, 2 - balloon dilatator), B - PTCG after dilatation: a visible enlarged zone of HJA (note the arrow) and free entry of the contrast agent into the jejunum loop (1), C - endoscopic photo: 1 - hepaticojunoanastomosis, 2 - balloon, 3 - conductor
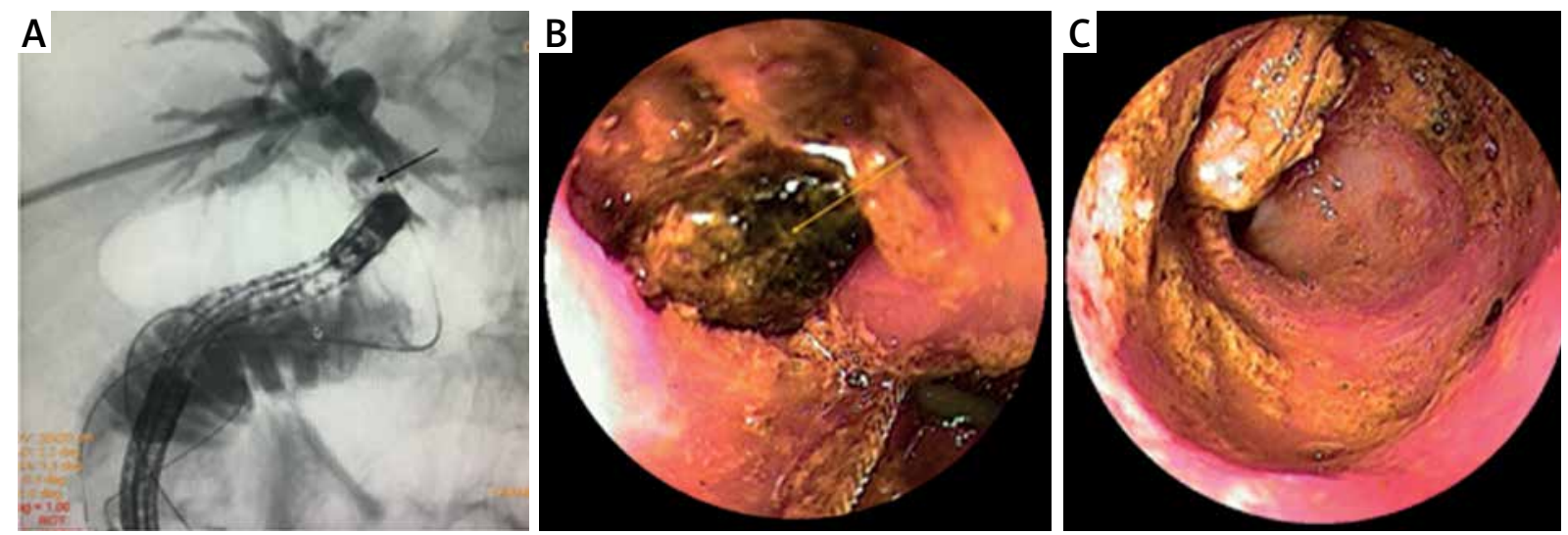

Photo 5. A - Percutaneous transhepatic cholangiography (the arrow shows a concrement above the HJA, B - endoscopic image (the arrow shows a large concrement in the lumen of HJA), C - endoscopic image: free lumen of the HJA zone after lithoextraction 
Table I. Minimally invasive interventions for strictures of HJA complicated by cholangiolithiasis

\begin{tabular}{|c|c|c|c|}
\hline Pathology before the surgery & Type of primary operation & Option of minimally invasive treatment & $N$ \\
\hline Tumor of the pancreatic head & Pancreatoduodenal resection & $\begin{array}{c}\text { Percutaneous transhepatic cholangioscopy + } \\
\text { laser lithotripsy + balloon dilatation of HJA with } \\
\text { lithoextraction }\end{array}$ & 1 \\
\hline Cholangiocarcinoma & Pancreatoduodenal resection & $\begin{array}{l}\text { "Rendezvous" procedure: percutaneous } \\
\text { transhepatic balloon dilatation of HJA + DBE with } \\
\text { lithoextraction }\end{array}$ & 1 \\
\hline \multirow{3}{*}{$\begin{array}{l}\text { Post-traumatic stricture of the } \\
\text { common hepatic duct }\end{array}$} & \multirow{3}{*}{$\begin{array}{c}\text { Roux-en-Y } \\
\text { hepaticojejunostomy }\end{array}$} & DBE-laser recanalization & 7 \\
\hline & & $\begin{array}{l}\text { Percutaneous transhepatic balloon dilatation } \\
\text { with lithoextraction + stenting of the HJA zone }\end{array}$ & 2 \\
\hline & & DBE-lithoextraction & 1 \\
\hline
\end{tabular}
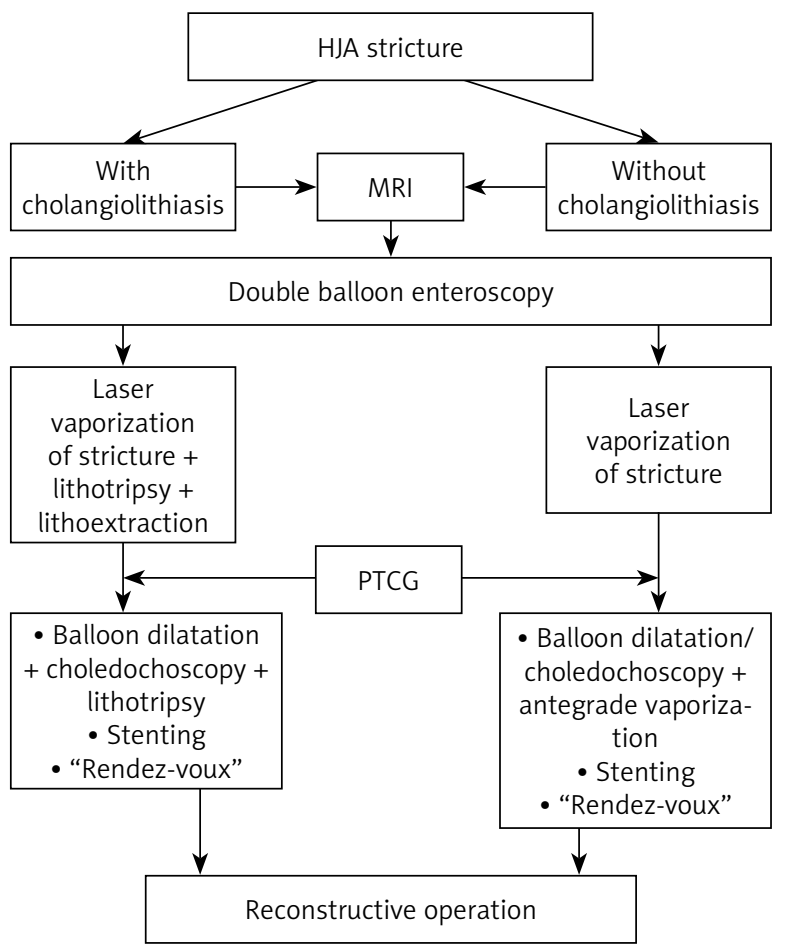

Figure 1. Treatment-diagnostic algorithm of HJA strictures

culties in performing DBE in case of surgically altered anatomy of the small bowel.

In the period from 2002 to 2016 we treated 58 patients with strictures of HJA after previous reconstructive operations on the bile ducts. Thirteen (22.4\%) patients developed intrahepatic cholangiolithiasis within 1 to 3 years of the postoperative period. Minimally invasive operations were performed on $12(20.7 \%)$ patients, and repeated reconstructive operations on 46 (79.3\%) patients (Table I).
Undoubtedly, present day medical advances and patients' needs spur and facilitate new approaches to treatment. Thus, we have developed and implemented a rare and innovative "rendezvous" technique (percutaneous transhepatic lithotripsy and antegrade balloon dilatation of stricture of HJA with simultaneous retrograde DBE) that can be applied to patients with surgically altered anatomy of the jejunum.

The suggested treatment-diagnostic algorithm allows one not only to identify the stricture and intrahepatic concrements, but also to prevent stone formation using minimally invasive antegrade and retrograde interventions to restore the patient's biliary drainage (Figure 1).

\section{Conclusions}

The methods of corrective treatment of strictures of HJA combined with cholangiolithiasis as a follow-up to reconstructive operations on the bile ducts are a priority tool for elderly patients with a concomitant pathology. Nowadays, the combination of antegrade balloon recanalization or laser vaporization of stricture of HJA with retrograde DBE and extraction of concrement fragments is recognized as a new, efficacious and safe treatment of cholangiolithiasis and strictures of HJA.

\section{Conflict of interest}

The authors declare no conflict of interest.

\section{References}

1. Galperin El, Chevokin AY. Factors determining the selection of the operation when "fresh" damage to the main bile duct. Annaly Khirurgicheskoy Gepatologii 2009; 14: 49-56. 
2. Schmidt SC, Langrehr JM, Hintze RE, Neuhaus P. Long-term results and risk factors influencing outcome of major bile duct injuries following cholecystectomy. Br J Surg 2005; 92: 76-82.

3. Bonnel DH, Fingarhut AL. Percutaneous transhepatic balloon dilatation of benign bilioenteric strictures. Long-term results in 110 patients. Am J Surg 2012; 203: 675-83.

4. Gastaca M. Biliary complications after orthotopic liver transplantation: a review of incidence and risk factors. Transplant Proc 2012; 44: 1545-9.

5. Jung JY, Lee SK, Oh HC, et al. The role of percutaneous transhepatic cholangioscopy in patients with hilar strictures. Gut Liver 2007; 1: 56-62.

6. Yang D, Lee SK, Moon S, et al. Percutaneous transhepatic cholangioscopic intervention in the management of complete membranous occlusion of bilioenteric anastomosis: report of two cases. Gut Liver 2009; 3: 352-5.

7. Negi SS, Sakhuja P, Malhora V, Chaundhary A. Factors predicting advances hepatic fibrosis in patients with postcholecystectomy bile duct strictures. Arch Surg 2004; 139: 299-303.

8. Quintero GA, Patino JF. Surgical management of benign strictures of biliary tract. World J Surg 2001; 25: 1245-50.

9. Chapman WC, Halevy A, Blumgart LH, Benjamin IS. Postcholecystectomy bile duct strictures. Management and outcome in 130 patients. Arch Surg 1995; 130: 597-604.

10. Sicora SS. Management of post-cholecystectomy benign bile duct strictures: review. Indian J Surg 2012; 74: 22-8.

11. Oh CH. Percutaneous transhepatic cholangioscopy in bilioenteric anastomosis stricture. Clin Endosc 2016; 49: 530-2.

12. Tulin Al, Shavlovskis J. Percutaneous transhepatic drainage of the Y-shaped catheter system in recurrent cicatricial strictures of the bile ducts. Annaly Khirurgicheskoy Gepatologii 2016; 21: 47-54.

13. Rdzanek L, Kalinowski P, Kozieł S, et al. Multiple plastic stents for benign extrahepatic biliary strictures: report of a case. Videosurgery Miniinv 2015; 10: 342-6.

14. Mueller PR, van Sonnenberg E, Ferrucci JT, et al. Biliary stricture dilatation: multicenter review of clinical management in $73 \mathrm{pa}$ tients. Radiology 1986; 160: 17-22.

Received: 26.07.2017, accepted: 2.10.2017. 